\title{
Topics
}

Ceren Ertan Yörük*

\section{The Effect of Alcohol Consumption on Labor Market Outcomes of Young Adults: Evidence from Minimum Legal Drinking Age Laws}

\begin{abstract}
This paper uses a regression discontinuity design to estimate the impact of the minimum legal drinking age (MLDA) laws on alcohol consumption and labor market outcomes of young adults. Using confidential data from the National Longitudinal Survey of Youth 1997 Cohort (NLSY97), I find that granting legal access to alcohol at age 21 leads to an increase in several measures of alcohol consumption. The discrete jump in the alcohol consumption at the MLDA has also negative spillover effects on the labor market outcomes of young adults. In particular, I document that the MLDA is associated with a 1 hour decrease in weekly working hours. However, the effect of the MLDA laws on wages is negative only under certain specifications. These results suggest that the policies designed to curb drinking may not only have desirable effects in reducing alcohol consumption among young adults but also have positive spillover effects on their labor market outcomes.
\end{abstract}

Keywords: alcohol consumption, employment, minimum legal drinking age, wages

JEL Classification: I10, I18, J10, J20

DOI 10.1515/bejeap-2014-0104

\section{Introduction}

Abuse of alcohol has been linked to several undesirable social outcomes, including crime, traffic accidents, mortality, and risky behavior. For instance, according to the recent National Highway Safety Administration data, in 2008, $37 \%$ of traffic fatalities in the United States were alcohol related. Furthermore, Carpenter and Dobkin (2009) and Markowitz (2005) document the negative

*Corresponding author: Ceren Ertan Yörük, School of Management, Sage College of Albany, 140 New Scotland Ave., Albany, NY 12208, USA, E-mail: yorukc@sage.edu 
impact of alcohol consumption on crime. The spillover effects of alcohol consumption on labor market outcomes are also extensively studied. In general, evidence on the relationship between alcohol consumption and labor market outcomes is mixed. On the one hand, some studies document that alcohol consumption has negative effects on labor market productivity, resulting in lower working hours and earnings. ${ }^{1}$ On the other hand, some studies find that drinking habits and labor market outcomes are unrelated or that moderate alcohol consumption is positively associated with labor productivity, probability of employment, and earnings. ${ }^{2}$

Identifying the causal effect of alcohol consumption on labor market outcomes is difficult since some unobserved characteristics that are correlated with alcohol consumption such as family background, health status, or risk preferences may also be associated with labor market outcomes. In order to address this endogeneity problem, several studies use instrumental variables for alcohol consumption such as percentage of the state's population residing in dry counties in which sale of alcohol is not allowed, the average beer price in the state, parents' and other distant relatives' consumption of alcohol, cigarette and alcohol taxes, apparent ethanol consumption, an indicator for having at least one parent with alcohol problems, and the age of onset of drinking regularly (Kenkel and Ribar 1994; Mullahy and Sindelar 1996; Renna 2008). Most of these instruments are based on state- or county-level alcohol control policies. However, Miron and Tetelbaum (2007) argue that unobserved differences at the state level are also associated with drinking habits. Moreover, some of the instrumental variables such as state-level taxes have been found to be a weak instrument for alcohol consumption. ${ }^{3}$

A large number of studies address this identification problem using the state-level variation in the minimum legal drinking age (hereafter, MLDA) that occurred before $1988 .{ }^{4}$ Using the variation in the MLDA laws reduces some of the concerns about policy endogeneity because the federal government threatened

1 See, for instance, Rice et al. (1990), Kenkel and Ribar (1994), Mullahy and Sindelar (1993,1996), Bray (2005).

2 For example, French and Zarkin (1995) suggest an inverse U-shaped relationship between alcohol consumption and wages. Additionally, Cook and Moore (2000) summarize the literature on the effects of alcohol consumption on labor productivity. They argue that both female and male light to moderate alcohol users have higher earnings, but alcohol-dependent men earn less. They also find that alcohol consumption has little to no effect on labor supply.

3 Manning, Blumberg, and Moulton (1995), Manning and Mullahy (1998), and Dave and Kaestner (2002) document that variation in alcohol prices or taxes causes only slight differences in alcohol consumption, which results in small differences in labor market outcomes.

4 Since 1988, all states adopted a uniform MLDA of 21. 
states with the loss of federal highway funds if they did not adopt an MLDA of 21. However, states where a lower MLDA was imposed might be different in unobserved ways than those states where an MLDA of 21 was enforced. If these unobserved differences at the state level are also associated with drinking habits of young adults, than one cannot estimate a consistent effect of the MLDA on alcohol consumption using the simple variation of the MLDA law at the state level.

In this paper, I address the potential endogeneity of alcohol consumption by using a regression discontinuity (RD) design and exploiting the discrete jump in alcohol consumption at age 21. To my knowledge, this is the first paper to study the effects of alcohol consumption on labor market outcomes using a RD framework. The main identifying assumption in this context is that the observed and unobserved determinants of these outcomes are likely to be distributed smoothly across the age-21 cutoff (MLDA). ${ }^{5}$ Hence, the changes in alcohol consumption and labor market outcomes at age 21 can solely be attributed to the MLDA law itself. My approach is comparable to Carpenter and Dobkin (2009), Carrell, Hoekstra, and West (2011), and Yörük and Ertan Yörük (2011). Carpenter and Dobkin (2009) investigate the effect of the MLDA on alcohol consumption and alcohol consumption-related mortalities using the RD design. They find that granting legal access to alcohol at age 21 leads to large increases in several indicators of alcohol consumption. Similarly, Carrell, Hoekstra, and West (2011) exploit the discontinuity in drinking at age 21 and find that alcohol consumption is associated with significant reductions in academic performance, particularly for the highest performing students. Yörük and Ertan Yörük (2011) also use a RD design to estimate the impact of the MLDA laws on alcohol consumption, smoking, and marijuana use among young adults. They document that MLDA leads to an increase in several indicators of alcohol consumption but the effect of the MLDA on smoking and marijuana use is small and often insignificant. In this paper, in contrast to Carpenter and Dobkin (2009), I employ a different individual-level survey (confidential version of the National Longitudinal Survey of Youth, 1997 Cohort (NLSY97)) that contains information on the exact birth day of the respondents. The NLSY97 has also the advantage of containing a more comprehensive range of alcohol consumption and alcohol consumption-related outcomes than previous research. Furthermore, in contrast to Carpenter and Dobkin (2009) and Yörük and Ertan Yörük (2011), I investigate the effect of the MLDA not only on alcohol consumption but also on labor market outcomes. Following Carpenter and Dobkin (2009), I combine the reduced form estimates of the effect of the MLDA laws on alcohol consumption with the estimates of their impact on labor market outcomes to obtain the indirect least squares estimate of the impact of alcohol consumption on the labor market outcomes.

5 This assumption is partially testable. I present the relevant tests in Section 4. 
Understanding the effect of the MLDA is of particular interest to policy makers not only because alcohol consumption is related to several undesirable health and economic outcomes, but also because lowering the MLDA from 21 is a current policy debate in many states. Proponents of a lower MLDA argue that imposing an age limit at 21 encourages a majority of college students under age 21 to consume alcohol in an irresponsible manner and that lowering the drinking age would help young adults to learn how to drink gradually, safely, and in moderation. However, opponents of lowering the drinking age argue that states that previously lowered the drinking age to 18, such as Massachusetts, Michigan, and Maine, experienced an increase in alcohol-related traffic accidents among the 18-20 age group. Furthermore, allowing teens to consume alcohol at age 18 can make them more vulnerable to drug and substance abuse, unplanned and unprotected sex, depression, and violence.

Using data from the NLSY97, I first compare the alcohol consumption behavior and labor market outcomes of young adults who are just about to turn 21 with those who recently turned 21. I find that granting legal access to alcohol at the MLDA leads to a discontinuous jump in the alcohol consumption. In particular, I document that those who are slightly older than 21 are 12 percentage points more likely to consume alcohol and drink 1.9 days more per month compared with those who are slightly younger than 21. I also document that the MLDA increases the probability of binge drinking by 10 percentage points and increases binge drinking days by 0.6 days more per month. The discontinuous jump in alcohol consumption also has negative spillover effects on the labor market outcomes of young adults. I find that the MLDA is associated with a 1 hour decrease in average weekly working hours and under certain specification, up to a 2.2 hour decrease in weekly working hours in the most recent job. I also find some evidence that the average weekly wages of young adults decrease at the MLDA. However, this effect is significant only under certain specifications. I also document that the MLDA does not have a significant impact on the probability of being employed. Following Carpenter and Dobkin (2009), I provide indirect least squares estimate of alcohol consumption on labor market outcomes. I find that a 1 day increase in drinking per month is associated with a 0.7 hour decrease in average weekly working hours and a 0.2 hour decrease in weekly working hours in the most recent job.

The rest of this paper is organized as follows. The next section presents the data and discusses the relationship between the MLDA and alcohol consumption. Section 3 sets out the specifications for different empirical models. Section 3 presents the results and discusses the robustness of the main findings. The last section summarizes the results and concludes. 


\section{Data}

In this paper, I use a restricted version of the NLSY97 for the empirical analysis. The NLSY97 includes 9,022 respondents who were born between 1980 and 1984 and were first interviewed in 1997. In the first round, both the eligible youth and one of that youth's parents received hour-long personal interviews. Since then, youths are continued to be interviewed on an annual basis. In the NLYS97, in addition to standard demographic information, the survey respondents were also asked about their drinking habits and labor market outcomes. I present the description of key variables that are used in the empirical analysis and their summary statistics in Appendix Table 4.

The confidential version of the NLSY97 contains information on respondents' exact date of birth and exact interview date for each survey year. I use this information to calculate the exact age in days for each respondent at the time of the interview. I restrict the sample to those respondents who were surveyed over the period 2000-2006and were at most 548 days younger or older than $21 .^{6}$

In the NLSY97, the respondents were first asked whether they consumed alcohol since the date of their last interview (DLI). Those who reported to have consumed alcohol at least once since the DLI were also asked about their alcohol consumption habits over the past month. This relatively short reference period is desirable since my empirical strategy compares those who are slightly older than 21 with those who are slightly younger than 21. In my analysis, I use both discrete indicators and continuous indicators of alcohol consumption. This is important since the relationship between alcohol consumption and labor market outcomes may be sensitive to the selection of alternative indicators of alcohol consumption. Two of the discrete measures of alcohol consumption that I consider are whether the respondent consumed alcohol over the past month and whether the respondent engaged in binge drinking in the past month. ${ }^{7}$ I also consider the number of days that the respondent had at least one drink and the

6 Alternatively, Carpenter and Dobkin (2009) and Yörük and Ertan Yörük (2011) use a 732 day bandwidth. This alternative bandwidth also yields similar results.

7 NLSY97 does not contain these binary variables directly. The respondents were asked the following questions: "During the last 30 days, on how many days did you have one or more drinks of an alcoholic beverage?" and "On how many days did you have five or more drinks on the same occasion during the past 30 days? By occasion we mean at the same time or within hours of each other." The binary alcohol participation variables for the corresponding questions are coded unity if the respondent reported consuming alcohol on at least 1 day and zero otherwise. 
number of days that she had five or more drinks on the same occasion during the past month.

Figure 1 shows the change in young adults' probability of drinking 1 month before and 1 month after their 20th, 21st, and 22nd birthdays. The probability of drinking jumps more than 20 percentage points during the first few days following the 21st birthday. Furthermore, this effect seems to be the result of the MLDA law since the probability of drinking follows a smooth trend around the 20th and 22nd birthdays. The increase in the probability of drinking at age 21 seems to ease after the first 10 days following the 21st birthday. However, the probability of drinking for those who are slightly older than 21 remains higher compared with those who are about to turn 21.

In order to test the spillover effects of increased alcohol consumption at age 21 on labor market outcomes of young adults, I consider average weekly working hours, average weekly earnings, and the probability of being employed. ${ }^{8}$ I also consider similar outcomes from the respondent's most recent job: the number of

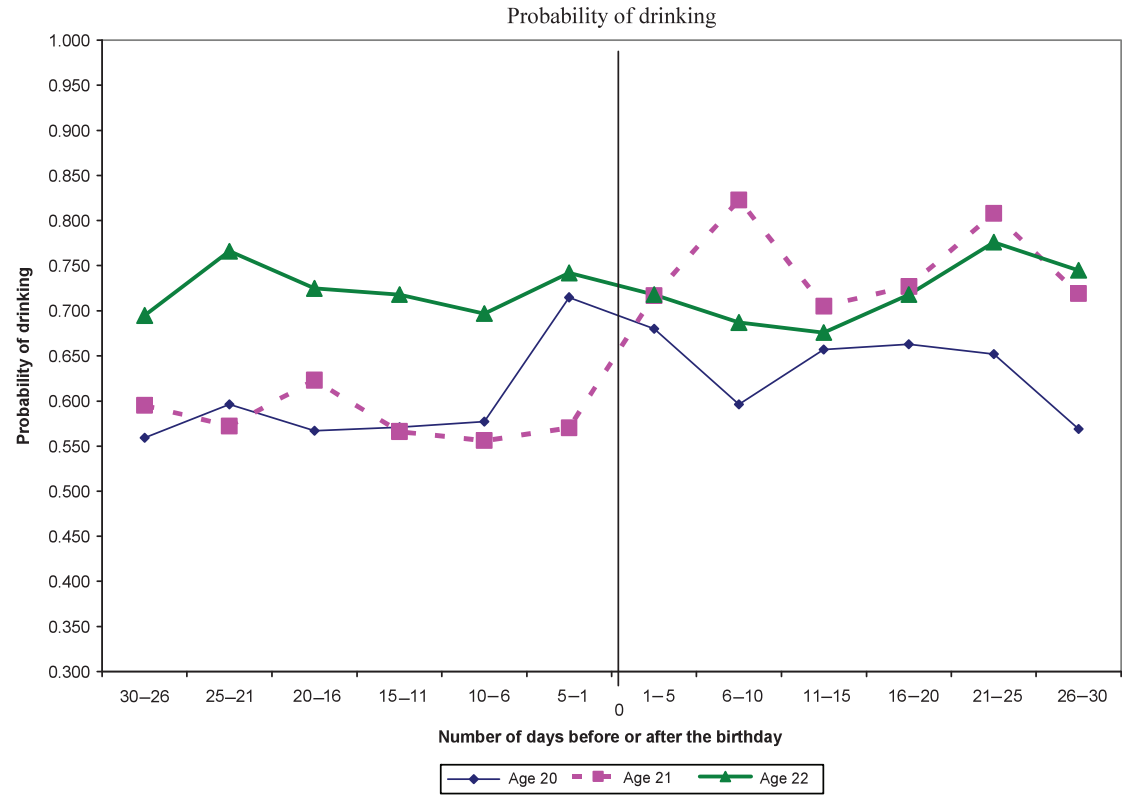

Figure 1: The changes in alcohol consumption trends 1 month before and 1 month after the 20th, 21st, and 22nd birthdays.

8 The respondents report their total annual working hours at employee-type jobs during the year. I calculated average weekly working hours simply by dividing the reported hours by 52 . 
hours worked per week and hourly wage rate. These variables are also directly reported by the respondents. In NLSY97, the respondents reported their weekly working hours as of either the job's stop date or the interview date for ongoing jobs.

\section{Methodology}

I use a RD design to estimate effect of the MLDA laws on alcohol consumption and labor market outcomes of young adults. ${ }^{9}$ This approach exploits the sudden increase in alcohol consumption that occurs at the MLDA. Since alcohol purchase and consumption are legally allowed according to this simple age cutoff, I was able to compare outcomes across youths with similar income, educational attainment, and other observable individual characteristics, but very different levels of alcohol consumption. The basic regression model I use for the empirical analysis is as follows:

$$
\text { outcome }_{i}=\beta^{\prime} X_{i}+\theta T_{i}+g\left(\text { age }_{i}\right)+u_{i}
$$

where outcome $e_{i}$ represents a particular outcome such as alcohol consumption or labor market outcome for individual $i$. The vector of observable characteristics is denoted by $X_{i}$ and includes household income, educational attainment, marital status, gender, and race of the respondent, a binary control for the employment status, as well as a dummy variable which controls for the birthday celebration effect. The birthday celebration effect dummy equals to one if the respondent was interviewed during the first month after turning 21. Since several observations are missing for household income, educational attainment, and marital status, I use dummy variables controlling for the missing observations for these set of covariates. In general, these control variables vary smoothly over age 21 . Hence, they have little effect on the estimates of the discontinuity and serve mainly to increase the precision of the estimates. The binary treatment variable is denoted by $T_{i}$ and takes the value of unity if the respondent is at least 21 years old at the interview date and zero otherwise. The coefficient of the main interest, $\theta$, denotes the effect of the MLDA law on the relevant outcome. Finally, $g\left(a e_{i}\right)$ is a smooth function of age profile, which is also known as the forcing variable in the context of RD design. Since NLSY97 reports the exact birth and interview date for each respondent, I was able to calculate the difference between the

9 Imbens and Lemieux (2008) and Lee and Lemieux (2009) present a detailed discussion of RD design and related issues. 
interview date and the respondent's 21st birthday in days. Therefore, for each respondent, the variable age ${ }_{i}$ represents the number of days before or after the 21st birthday.

Modeling the smooth function of age profile correctly is one of the main problems in implementing the RD design. Although it is common in RD analysis to control for high-order polynomials of the forcing variable, in a recent paper, Gelman and Imbens (2014) argue that the use of high-order polynomials can be misleading and suggest to use estimators based on local linear or quadratic polynomials or other smooth functions. In this paper, my main results rely on the estimates from the models that contain a linear polynomial of the running variable. However, as a robustness check, I also present results from parametric models that contain higher polynomials of the running variable (i.e., quadratic and cubic splines) and from non-parametric models. The general parametric model with different degrees of polynomials that are fully interacted with the treatment can be written as

$$
\text { outcome }_{i}=\beta^{\prime} X_{i}+\theta T_{i}+\sum_{j=1}^{n} \alpha_{j} \operatorname{age}_{i}^{j}+\sum_{j=1}^{n} \lambda_{j}\left(T_{i} \times \operatorname{age}_{i}^{j}\right)+u_{i} \quad \text { for } n=\{1,2,3\}
$$

For the non-parametric specifications, following Hahn, Todd, and van der Klaauw (2001), I use local linear regressions to estimate the left and right limits of discontinuity at age 21 . The difference between the two limits is interpreted as the local treatment effect of the MLDA law on outcome variables. Lee and Lemieux (2009) argue that a transparent way of putting more weight on observations close to the cutoff is to estimate non-parametric models with a rectangular kernel using relatively smaller bandwidths. Following Lee and Lemieux (2009), I estimate the non-parametric specifications using a rectangular kernel. ${ }^{10}$

The remaining estimation issue for the non-parametric models is the selection of appropriate bandwidth. Since the RD is identified only at the discontinuity, it is important to balance the goals of staying as local to the cutoff point at age 21 as possible while ensuring to have enough data to get informative estimates. Following Ludwig and Miller (2007) and Yörük and Ertan Yörük (2011), I consider a broad range of candidate bandwidths. I start with a bandwidth of 240 and also consider bandwidths that are twice (480), and half (120)

10 I also estimate my models using a triangular kernel. Although not reported here, as in previous studies, the choice of kernel has little effect on my estimates (Fan and Gijbels 1996). 
the size of this bandwidth. ${ }^{11}$ For the non-parametric models, I calculate the standard errors using the bootstrap procedure with 1,000 replications, which may offer more accurate asymptotic inference than the analytic standard errors (Cameron and Trivedi 2005).

The RD approach also allows one to estimate the direct effect of alcohol consumption on labor market outcomes. Following Carpenter and Dobkin (2009), one can express the relationship between a particular labor market outcome and alcohol consumption as

$$
\text { labor }_{i}=\gamma^{\prime} X_{i}+\delta \text { alcohol }_{i}+f\left(\text { age }_{i}\right)+e_{i}
$$

where labor $_{i}$ is the labor market outcome of individual $i$, alcohol ${ }_{i}$ is a measure of alcohol consumption, $f\left(\mathrm{age}_{i}\right)$ is a smooth function of the age profile, and $e_{i}$ is an idiosyncratic error term. Additionally, suppose that alcohol consumption is determined by the following model in the first stage:

$$
\text { alcohol }_{i}=\eta^{\prime} X_{i}+\phi T_{i}+h\left(\text { age }_{i}\right)+v_{i}
$$

where $\phi$ denotes the discrete jump in alcohol consumption at the MLDA, $h\left(\mathrm{age}_{i}\right)$ is the age profile, and $v_{i}$ is the error term. Equations (3) and (4) imply a reduced-form model similar to eq.[1], in which the effect of reaching age 21 on the outcome is $\theta=\delta \times \phi$. Thus, the causal effect of alcohol consumption on the labor market outcome, $\delta$, can be estimated by the ratio of the estimated discontinuity in labor market outcome at age 21 to the estimated discontinuity in alcohol consumption.

\section{Results}

This section reports the estimation results from several parametric and nonparametric models. I first test whether there exists other changes in observable characteristics of young adults occurring at age 21 that could confound the RD design. To do this, following Lee and Lemieux (2009), I estimate eq.[2] separately for all control variables using a quadratic spline. ${ }^{12}$ The results reported in Appendix Table 5 suggest that for each covariate, the coefficient of the

11 I also estimate non-parametric models using the bandwidth selection procedure suggested by Imbens and Kalyanaraman (2012). However, I observe that Imbens and Kalyanaraman's optimal bandwidths are extremely small and oversmooth the data. Hence, the results are not reported here. The same problem is also discussed in Malamud and Pop-Eleches (2011).

12 Following the previous literature, my selection of a quadratic polynomial is a result of a visual inspection of data for the best fit. Estimating this model separately for all control variables using linear or cubic splines yields similar results. 
treatment variable is insignificant. ${ }^{13}$ Therefore, there is no evidence of significant change in observable characteristics of young adults at the MLDA. ${ }^{14}$ Additionally, Appendix Figure 4 shows the corresponding age profiles of selected control variables. The quadratic prediction of each selected covariate appears to fit the actual data well and exhibits either no or statistically insignificant jump at the MLDA. One cannot test whether the unobservable characteristics of the young adults vary smoothly across the discontinuity directly. However, the fact that observable characteristics of young adults are smoothly distributed around age 21 reduces the concerns about omitted variables' bias and suggests that parametric models estimated with or without controls should yield similar results.

Another possible concern for identification in a RD design comes from the possibility of nonrandom sorting of young adults to either side of the age-21 cutoff. In order to test this, I used McCrary's (2008) test, which provides an estimator for the discontinuity at the cutoff in the density function of the running variable. The test is implemented as a Wald test of the null hypothesis that the discontinuity is zero. I fail to reject this null hypothesis (Wald statistic $=0.045$ and standard error $=0.059$ ). I also examine the possibility of nonrandom sorting graphically. Appendix Figure 5 shows that the distribution of the frequency of observations is smooth across the MLDA and hence, there is little evidence of nonrandom sorting around age 21. Since the empirical results are based on self-reported survey data, youths under the MLDA may also be more likely to underreport their alcohol consumption since alcohol consumption is illegal for this age group. This could generate a discrete jump in reported level of alcohol consumption at age 21 even if there is no true change in actual behavior. However, Figure 1 shows that, alcohol consumption patterns of 20-year-olds are very similar compared with 21- and 22-year-olds, which suggests that the empirical results documented in this paper are not subject to an underreporting bias.

13 In Appendix Table 5, I test whether the ln(income) is distributed smoothly around the cutoff age of 21. In empirical models, rather than using a continuous measure of income, I use dummy variables controlling for different income ranges and missing information on income. Models estimated using $\ln$ (income) yield comparable results.

14 The only exception is obtaining a high school degree. However, this variable is marginally significant at the $10 \%$ significance level. Furthermore, I control for this variable in my regression models and models estimated without control variables yield very similar results compared with those estimated with control variables.This result further shows that observable characteristics of young adults exhibit a smooth trend around the MLDA. 


\subsection{Alcohol consumption}

In Table 1, I present the effect of the MLDA on alternative indicators of alcohol consumption among young adults. The first column of Table 1 reports the estimates of the effect of the MLDA on the probability of alcohol consumption in the past month. The parametric models include linear, quadratic, and cubic polynomials in age fully interacted with a dummy variable indicating an age over 21 and are estimated using sample weights. ${ }^{15}$ All parametric regressions include a set of control variables which are presented in Appendix Table 4. The results shows that the effect of the MLDA on probability of drinking is robust to the selection of the degree of polynomial in parametric models. The estimates from alternative parametric models suggest that the probability of drinking among young adults tends to increase 10-17 percentage points at age 21 . Nonparametric models estimated using rectangular kernel with several different

Table 1: The effect of the MLDA on alcohol consumption.

\begin{tabular}{lcccc}
\hline & Alcohol & Binge & Days alcohol & Days binge \\
\hline Parametric models & & & & \\
Linear & 0.100 & 0.077 & 1.677 & 0.559 \\
& $(0.012)^{\star \star \star}$ & $(0.013)^{\star \star \star}$ & $(0.162)^{\star \star \star}$ & $(0.120)^{\star \star \star}$ \\
Quadratic & 0.124 & 0.102 & 1.847 & 0.578 \\
& $(0.022)^{\star \star \star}$ & $(0.026)^{\star \star \star}$ & $(0.324)^{\star \star \star}$ & $(0.240)^{\star \star}$ \\
Cubic & 0.169 & 0.130 & 2.006 & 0.788 \\
& $(0.033)^{\star \star \star}$ & $(0.039)^{\star \star \star}$ & $(0.495)^{\star \star \star}$ & $(0.360)^{\star \star}$ \\
No of observations & & & & \\
& 22,319 & 20,019 & 22,319 & 20,019 \\
Non-parametric models & & & & \\
Bandwidth $=120$ & 0.166 & 0.143 & 1.230 & 0.220 \\
& $(0.027)^{\star \star \star}$ & $(0.028)^{\star \star \star}$ & $(0.453)^{\star \star \star}$ & $(0.370)$ \\
Bandwidth $=240$ & 0.118 & 0.103 & 1.292 & 0.387 \\
& $(0.020)^{\star \star \star}$ & $(0.020)^{\star \star \star}$ & $(0.314)^{\star \star \star}$ & $(0.249)$ \\
Bandwidth $=480$ & 0.101 & 0.085 & 1.394 & 0.283 \\
& $(0.014)^{\star \star \star}$ & $(0.014)^{\star \star \star}$ & $(0.221)^{\star \star \star}$ & $(0.180)$ \\
\hline
\end{tabular}

Notes: All parametric regressions include control variables as discussed in the text and are estimated using sample weights. The signs ${ }^{* \star}$ and ${ }^{* *}$ indicate the statistical significance at the $1 \%$ and $5 \%$ significance levels, respectively. For the parametric models, robust standard errors clustered at the individual level are reported in parenthesis. For the non-parametric models, standard errors are calculated using 1,000 bootstrap replications and reported in parenthesis.

15 Although not reported here, comparable parametric models estimated without sample weights yield similar results. 

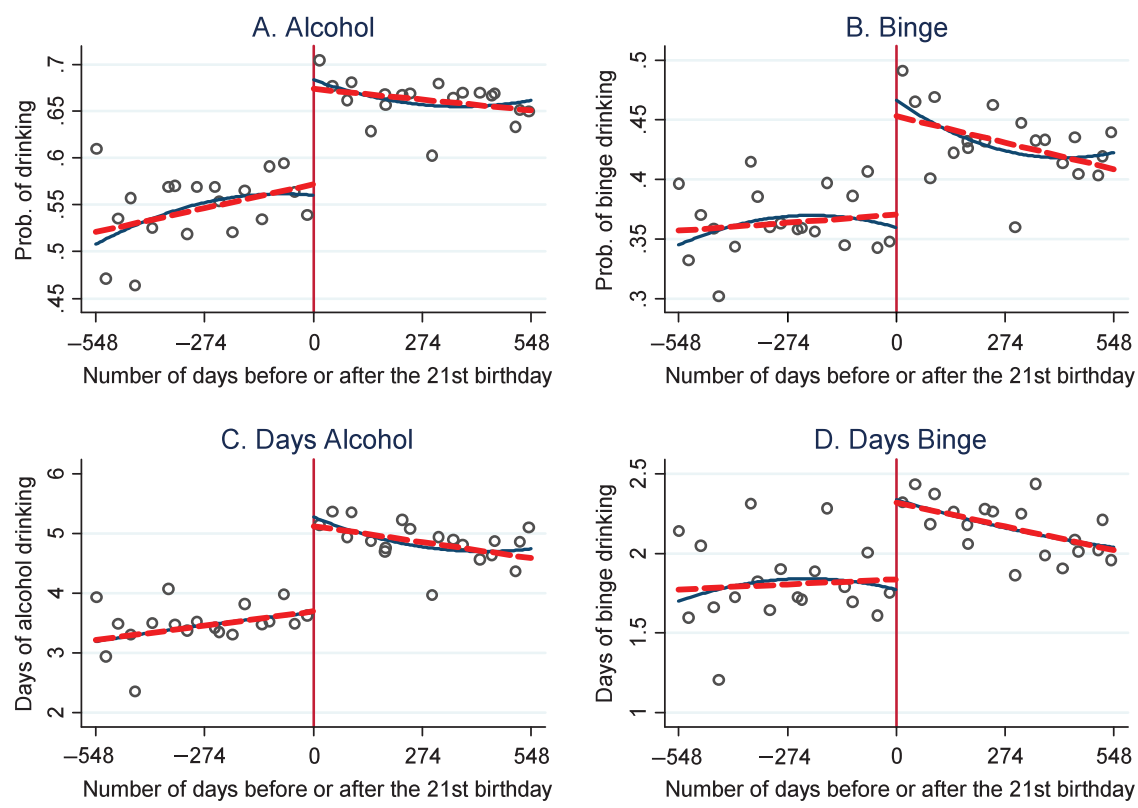

Figure 2: Alcohol consumption trends before and after the 21st birthday.

Notes: Mean of the outcome variables for 30 day intervals is plotted. The solid lines are a second-order polynomial fitted on individual observations on either side of the age-21 cutoff as reported in Table 1.

bandwidths ranging from 120 to 480 also yield similar results. In panel A of Figure 2, I superimpose the linear and quadratic fitted lines from the parametric model estimated without any controls over the mean value of the percent of drinkers calculated for each 30-day age block. The figure confirms the estimation results and shows that the probability of drinking exhibits a discrete jump at the MLDA.

The second column in Table 1 shows that under several different parametric and non-parametric specifications, the MLDA is also associated with a 8-14 percentage point increase in the probability of binge drinking. Panel B of Figure 2 also shows a jump in the probability of binge drinking at the age-21 cutoff.

The parametric specifications reported in the third and fourth columns in Table 2 show that young adults tend to consume alcohol up to 2 days more per month once they turn 21. Non-parametric models yield similar results and show up to a 1.4 day increase in the alcohol consumption at age 21. Panel C of Figure 2 also illustrates this increase. Results from the parametric models indicate a significant 0.6-0.8 day increase in the number of binge drinking days per month at age 21 . However, the results from the non-parametric specifications 
Table 2: The effect of the MLDA on labor market outcomes.

\begin{tabular}{|c|c|c|c|c|c|}
\hline & Avg hours & $\begin{array}{r}\text { Avg. weekly } \\
\text { earnings }\end{array}$ & $\begin{array}{r}\text { Hours worked per } \\
\text { week }\end{array}$ & $\begin{array}{r}\text { Hourly } \\
\text { pay }\end{array}$ & Employed \\
\hline \multicolumn{6}{|c|}{ Parametric models } \\
\hline Linear & $\begin{array}{l}-0.935 \\
(0.405)^{\star \star}\end{array}$ & $\begin{array}{l}-2.704 \\
(9.662)\end{array}$ & $\begin{array}{l}-0.555 \\
(0.416)\end{array}$ & $\begin{array}{l}-0.041 \\
(0.418)\end{array}$ & $\begin{array}{r}0.009 \\
(0.013)\end{array}$ \\
\hline Quadratic & $\begin{array}{l}-1.865 \\
(0.760)^{\star \star}\end{array}$ & $\begin{array}{l}-40.697 \\
(17.217)^{\star \star}\end{array}$ & $\begin{array}{l}-2.194 \\
(0.722)^{\star \star \star}\end{array}$ & $\begin{array}{l}-1.242 \\
(0.643)^{\star}\end{array}$ & $\begin{array}{r}0.005 \\
(0.022)\end{array}$ \\
\hline Cubic & $\begin{array}{l}-1.675 \\
(1.161)\end{array}$ & $\begin{array}{l}-13.270 \\
(25.575)\end{array}$ & $\begin{array}{l}-2.403 \\
(1.085)^{\star \star}\end{array}$ & $\begin{array}{l}-1.370 \\
(0.914)\end{array}$ & $\begin{array}{r}0.019 \\
(0.034)\end{array}$ \\
\hline No of obser & $\begin{array}{l}\text { ations } \\
\qquad 18570\end{array}$ & 11567 & 17690 & 17473 & 19102 \\
\hline \multicolumn{6}{|c|}{ Non-parametric models } \\
\hline $\begin{array}{l}\text { Bandwidth } \\
120\end{array}$ & $\begin{aligned}= & -1.657 \\
& (0.899)^{*}\end{aligned}$ & $\begin{array}{r}-10.870 \\
(19.057)\end{array}$ & $\begin{array}{r}-1.113 \\
(0.832)\end{array}$ & $\begin{array}{l}-0.016 \\
(1.040)\end{array}$ & $\begin{array}{l}-0.022 \\
(0.024)\end{array}$ \\
\hline $\begin{array}{l}\text { Bandwidth } \\
240\end{array}$ & $\begin{aligned}= & -1.456 \\
& (0.665)^{\star \star}\end{aligned}$ & $\begin{array}{l}-27.405 \\
(13.691)^{\star \star}\end{array}$ & $\begin{array}{l}-1.145 \\
(0.583)^{\star \star}\end{array}$ & $\begin{array}{l}-0.265 \\
(0.679)\end{array}$ & $\begin{array}{l}-0.018 \\
(0.018)\end{array}$ \\
\hline $\begin{array}{l}\text { Bandwidth } \\
480\end{array}$ & $\begin{aligned}= & -1.288 \\
& (0.462)^{\star \star \star}\end{aligned}$ & $\begin{array}{l}-14.737 \\
(10.376)\end{array}$ & $\begin{array}{l}-0.784 \\
(0.408)^{\star \star}\end{array}$ & $\begin{array}{r}-0.092 \\
(0.471)\end{array}$ & $\begin{array}{l}-0.012 \\
(0.013)\end{array}$ \\
\hline
\end{tabular}

Notes: All parametric regressions include control variables as discussed in the text and are estimated using sample weights. The signs ${ }^{* \star *}, * \star, *$ indicate the statistical significance at the $1 \%, 5 \%$, and $10 \%$ significance levels, respectively. For the parametric models, robust standard errors clustered at the individual level are reported in parenthesis. For the non-parametric models, local linear regressions are estimated using a rectangular kernel. For the non-parametric models, standard errors are calculated using 1,000 bootstrap replications and reported in parenthesis.

for the effect of the MLDA on the number of binge drinking days are statistically insignificant. Panel D of Figure 2 shows a relatively small jump in the number of binge drinking days at age 21 followed by a decreasing trend in binge drinking.

In Appendix Table 6, I test whether the exclusion of the control variables changes the effect of the MLDA on alcohol consumption. In this table, I present the results from a parametric model estimated using a quadratic polynomial of age. Models estimated without control variables suggest that the MLDA is associated with a 13 percentage point increase in the probability of drinking, a 12 percentage point increase in the probability of consuming five or more drinks, a 1.7 day increase in the number of days that young adults consume alcohol per month, and a 0.5 day increase in the number of binge drinking days per month. These estimates are very similar compared with the estimates from the corresponding parametric models that contain a full set of control variables. 


\subsection{Labor market outcomes}

In Table 2, I report the estimates from parametric and non-parametric models of the effect of the MLDA law on several labor market outcomes. ${ }^{16}$ Overall, the results from the parametric models are mostly comparable with the estimates from the non-parametric models.

The first column of Table 2 reports the effect of the MLDA law on average weekly working hours. Both parametric and non-parametric models yield similar results and imply that the average weekly working hours decrease at the MLDA. ${ }^{17}$ On average, the MLDA is associated with a $0.95-1.87$ hour per week decrease in average weekly working hours. However, this effect is insignificant in a parametric model estimated using a cubic polynomial. Figure 3 illustrates
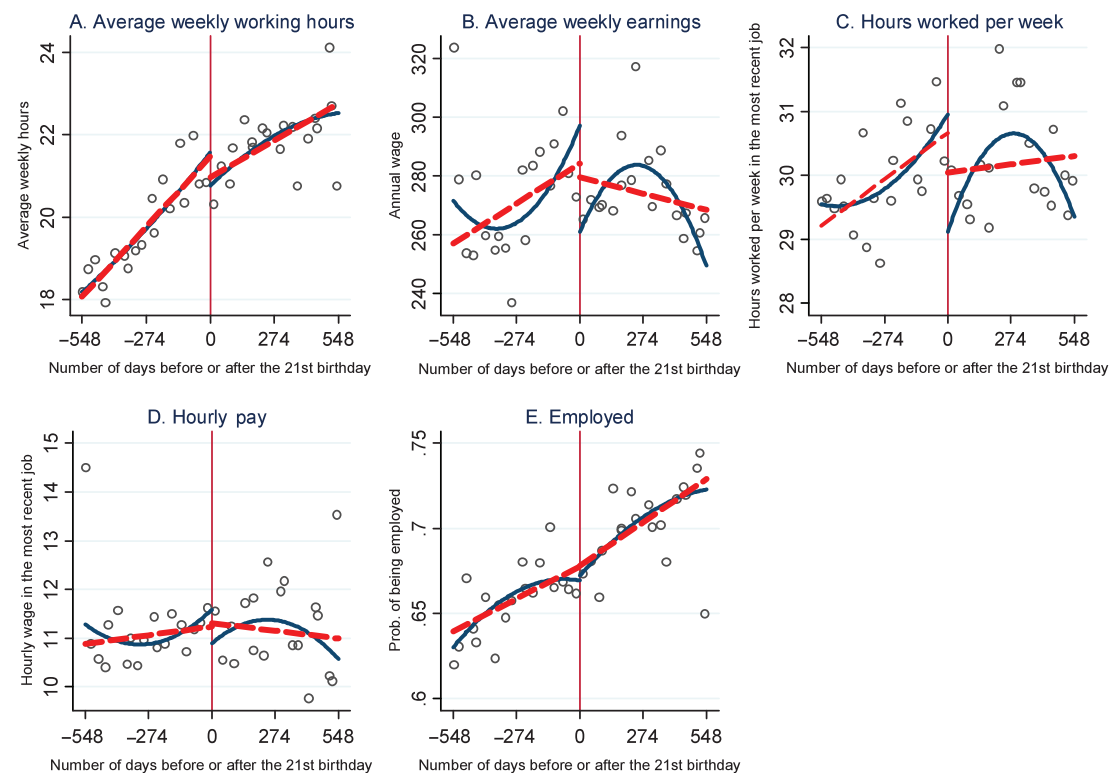

Figure 3: Trends in selected labor market outcomes before and after the 21st birthday. Notes: Mean of the outcome variables for 30 day intervals is plotted. The dashed lines are a linear polynomial fitted and solid lines are a second-order polynomial fitted on individual observations on either side of the age-21 cutoff as reported in Table 2.

16 I also present the estimates from locally weighted scatterplot smoothing (LOWESS) in Appendix Figure 6. The results from the LOWESS are also similar to those in Figure 3 and in Table 2.

17 In my estimation, I restrict my sample to those who reported positive working hours and earnings. I also estimate the same models for those who are not currently enrolled as a student. For this group, I find that the MLDA is negatively associated with average weekly working hours. This effect is significant at conventional significance levels. 
the labor market outcomes of young adults before and after their 21st birthday. In this figure, I superimpose the linear and quadratic fitted lines from the parametric model estimated without any controls over the mean value of the labor market outcome variables calculated for each 30-day age block. The figure in panel A shows the decrease in average weekly working hours at the age-21 cutoff. However, it also shows that following this decrease, young adults tend to increase their average weekly working hours. Following Carpenter and Dobkin (2009), I also estimate the direct effect of alcohol consumption on weekly working hours. Using the estimate from parametric regression estimated with linear polynomial, I find that a 1 day increase in drinking per month is associated with a 0.7 hour decrease in average weekly working hours.

Under certain specifications, the results on the second column of Table 2 show that the MLDA has a negative effect on average weekly wage of young adults. In particular, the estimates from parametric regression estimated with a quadratic polynomial of age suggest that the MLDA is significantly associated with a $\$ 41$ decrease in average weekly wages. This effect is relatively smaller but remains statistically significant under a non-parametric model estimated with a bandwidth of 240 . The results from the remaining parametric and non-parametric specifications are insignificant. Panel B of Figure 3 also shows a reduction in average weekly wages at the MLDA.

The third and fourth columns show the estimation results for the labor market outcomes in the most recent job. The effect of the MLDA law on weekly working hours is significant in parametric models estimated using quadratic and cubic polynomials of age and in the non-parametric models estimated with bandwidths of 240 and 480 . The results show that weekly working hours in the most recent job tend to decrease around 0.8-2.4 hours at the MLDA. Furthermore, panel $\mathrm{C}$ of Figure 3 shows a decrease in weekly working hours at the MLDA. Using the estimate from parametric regression estimated with a quadratic polynomial of age, I estimate the direct effect of alcohol consumption on weekly working hours on the most recent job. I find that a 1 day increase in drinking per month is associated with a 0.2 hour decrease in weekly working hours in the most recent job.

The impact of the discontinuity at the MLDA on hourly wage in the most recent job is negative but insignificant in all parametric and non-parametric specifications except for the parametric models estimated with a quadratic age polynomial. However, this effect is significant only at the $10 \%$ significance level. Consistent with the estimation results, panel D of Figure 3 shows a relatively small decrease in hourly wage in the most recent job.

Finally, the results reported in the last column of Table 2 reveal that the effect of the MLDA on the probability of being employed is insignificant in all 
parametric and non-parametric specifications. Panel E of Figure 3 also shows that there is no discrete jump in the probability of being employed at the MLDA.

I also test whether the exclusion of the control variables affects these results. In Appendix Table 7, I present the result of this sensitivity test using the estimates from parametric regressions estimated with a quadratic polynomial of age. The findings suggest that the MLDA is associated with a 2.2 hour decrease in average weekly working hours, a $\$ 47$ decrease in average weekly wage, a 1.8 hour decrease in weekly working hours in the most recent job, and a \$1.2 decrease in hourly wage in the most recent job. These estimates are very similar compared with the estimates from the corresponding parametric models that contain a full set of control variables.

\subsection{Robustness checks}

In this section, I investigate whether the effect of the MLDA on the labor market outcomes is sensitive to the selection of different subsamples. In Table 3, I present the results of this sensitivity test using the estimates from models that include linear or quadratic polynomial of the running variable.

Some of the young adults who are around the MLDA are college students. It is also possible that they work in a part-time job. In order to test whether the labor market effects of the MLDA law are sensitive to being a college student, I separately run regressions for those who are not enrolled in a college as of age 20 and for those who are enrolled in a college as of age 20. The first row of Table 3 reports the results from parametric models estimated for those who are not enrolled in a college as of age 20. The results show that the effect of the MLDA on the labor market outcomes of this group is very similar to the labor market effects of the MLDA for the full sample. For example, the results show that the increased alcohol consumption at the MLDA is associated with a 1.5-2.3 hour decrease in the weekly working hours for this group. Similarly, the results from the model estimated using a quadratic polynomial of age show that the weekly working hours in the most recent job significantly decrease by 2.7 hours at the MLDA. However, this effect is insignificant when the model is estimated with a linear polynomial of age. Furthermore, the results from the models that include a quadratic age polynomial suggest that the average weekly earnings decrease by $\$ 68$ at the MLDA. However, this effect becomes insignificant if the model is estimated with a linear age polynomial. Columns 7 and 8 of Table 3 show the estimated effect of the MLDA on the hourly wage in the most recent job for those who are not enrolled in college. Under all specifications, the estimated coefficient of the treatment variable is statistically insignificant. Similar to the main results reported in Table 2, the effect of the MLDA on the probability of being employed remains insignificant for this group as well. 


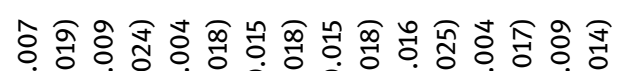

当

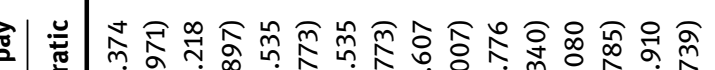

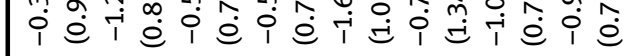

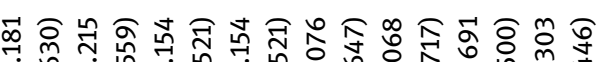
o

\section{$\frac{\pi}{*}$}

品

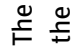

空范

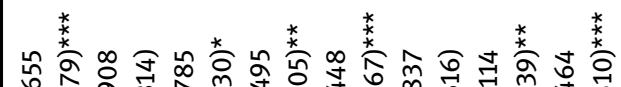

i่

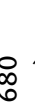

$\infty$

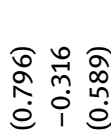

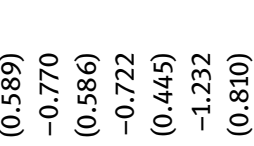

每

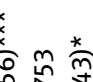
i

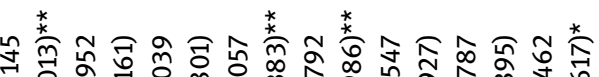

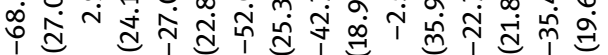

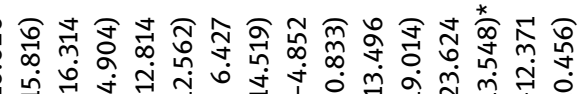

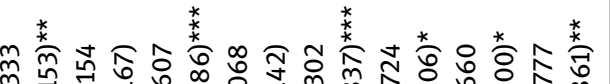

în

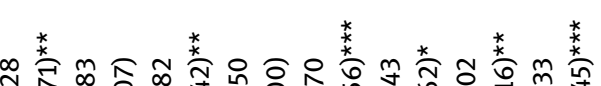

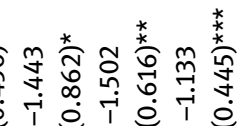

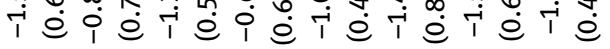

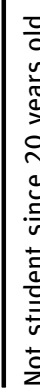

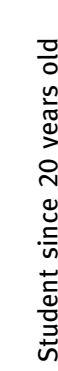

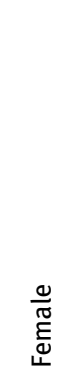

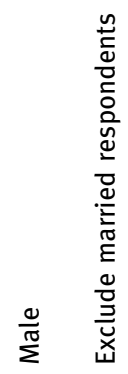

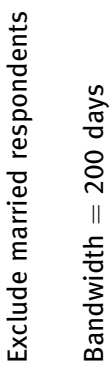

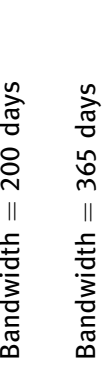

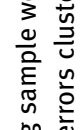

an $\frac{1}{n}$ 민 
The second row of Table 3 shows the effect of the MLDA on the labor market outcomes of those who are enrolled in a college as of age 20. The results suggest that the MLDA law does not have any significant impact on the labor market outcomes of this group of young adults.

I also run separate regressions for males and females to test whether the effect of the MLDA on the labor market outcomes of young adults differs by gender. The results on Table 3 show that the MLDA is associated with a 1.3-2.6 hour decrease in the average weekly working hours for females. For males, the results from models estimated using a quadratic polynomial of age suggest that the weekly working hours in the most recent job decrease by 2.5 hours at the MLDA. Additionally, increased alcohol consumption at the MLDA is associated with a \$52 decrease in the average weekly earnings for males. However, the effect of the MLDA on the average weekly earnings of females is not significant.

In my empirical analysis, I include both married and unmarried respondents. It is plausible to think that the drinking behavior of the married young adults is less likely to be affected by the MLDA law. In order to test this possibility, I exclude the married respondents from my sample and reestimate the effect of the MLDA on labor market outcomes of unmarried respondents. Results reported in the fifth row of Table 3 show that the main results are robust to the exclusion of married respondents from the sample.

In Table 3, I also test whether the relationship between the MLDA and weekly working hours in the most recent job is sensitive to the selection of alternative age bandwidths. In general, the models estimated using alternative age bandwidths yield comparable results. I find that the MLDA is associated with a 1.1-2.7 hour decrease in the average weekly working hours and a 0.7-2.5 hour decrease in the weekly working hours in the most recent job.

\section{Discussion of results and conclusion}

In this paper, I investigate the effect of the MLDA laws on alcohol consumption and labor market outcomes of young adults using a restricted version of the NLSY97, which contains information on the exact birth date of the respondents. While there has been a considerable amount of research on the effect of the MLDA laws on alcohol consumption and alcohol consumption-related outcomes, existing studies have two major limitations. First, although the decision to adopt a lower MLDA might be endogenous, most of the existing studies have made use of the changes in the MLDA laws that occurred in the 1970s and 1980s at the state level. Second, studies that explore the spillover effects of the MLDA laws on labor market outcomes are limited and no previous study has employed 
a RD approach to identify the effect of alcohol consumption on labor market outcomes of young adults.

Using a RD approach, I document that the MLDA of 21 is associated with a higher probability of alcohol consumption and binge drinking among young adults. My estimates suggest that the MLDA is associated with an approximate 12 percentage point increase in the probability of drinking. I also find that young adults who are just over 21 tend to drink 1.9 days more than those who are just under 21. I document that the MLDA law is associated with a 1.9 hour decrease in weekly working hours and a 2.2 hour decrease in weekly working hours in the most recent job. I also find that the impact of the MLDA on wages and the probability of being employed is statistically insignificant.

$\mathrm{RD}$ design is helpful to estimate the short-run effects of alcohol consumption on the labor market outcomes. Following Carpenter and Dobkin (2009), I combine the reduced form estimates of the effect of the MLDA laws on alcohol consumption with the estimates of their impact on labor market outcomes to obtain the implied instrumental variables estimate of the impact of alcohol consumption on the labor market outcomes. I find that a 1 day increase in drinking days per month is associated with a 1 hour decrease in average weekly working hours and a 1.2 hour decrease in weekly working hours in the most recent job. Although not reported in this paper, in order to show whether data from other sources support my main findings, I use data from the Current Population Survey (CPS). Specifically, I consider two main labor outcome variables from the CPS, which contain a short reference period: working hours during the last week, and the probability of being absent from work last week due to illness. I find that young adults tend to decrease their weekly working hours by up to 0.5 hours at the MLDA. Similarly, the probability of being absent from work due to illness increases by 5 percentage points at the MLDA. This can potentially explain the significant impact of the MLDA on working hours in the short run. The findings from the CPS data suggest that drinking is associated with lower productivity in terms of being absent in the work because of the hangover effect. However, the main limitation of using the CPS is that the survey does not contain information on the exact birth date of respondents. For this reason, it is difficult to correctly identify the control and the treatment groups. One needs a more detailed survey, which contains information on the exact birth dates and short reference periods for labor market outcomes to correctly identify the underlying mechanisms that could potentially explain the short-run effects of alcohol consumption on labor market outcomes of young adults.

I also show that the effect of the MLDA is more pronounced for those who are not enrolled to college and on the labor market as of age 20. I find that weekly working hours of this group of young adults decrease by 2.3 hours at the MLDA. 
Given that the mean of weekly working hours for this group is 23 hours per week, my findings imply that, once young adults are exposed to drinking, their weekly working hours decrease by $10 \%$. The findings of this paper are particularly important given the ongoing policy debates about stricter alcohol control targeted toward youth. The results indicate that policies that combat drinking may have desirable impacts and can create public health benefits. These policies may also have desirable spillover effects on several labor market outcomes of young adults.

Acknowledgments: This paper uses confidential data provided by the Bureau of Labor Statistics (BLS). The views expressed in this paper are those of the author and do not necessarily reflect those of the BLS. This paper has greatly benefited from the comments of William Dickens, Osborne Jackson, Andrew Sum, Maria Jose Luengo-Prado, and Barış K. Yörük.

\section{Appendix}
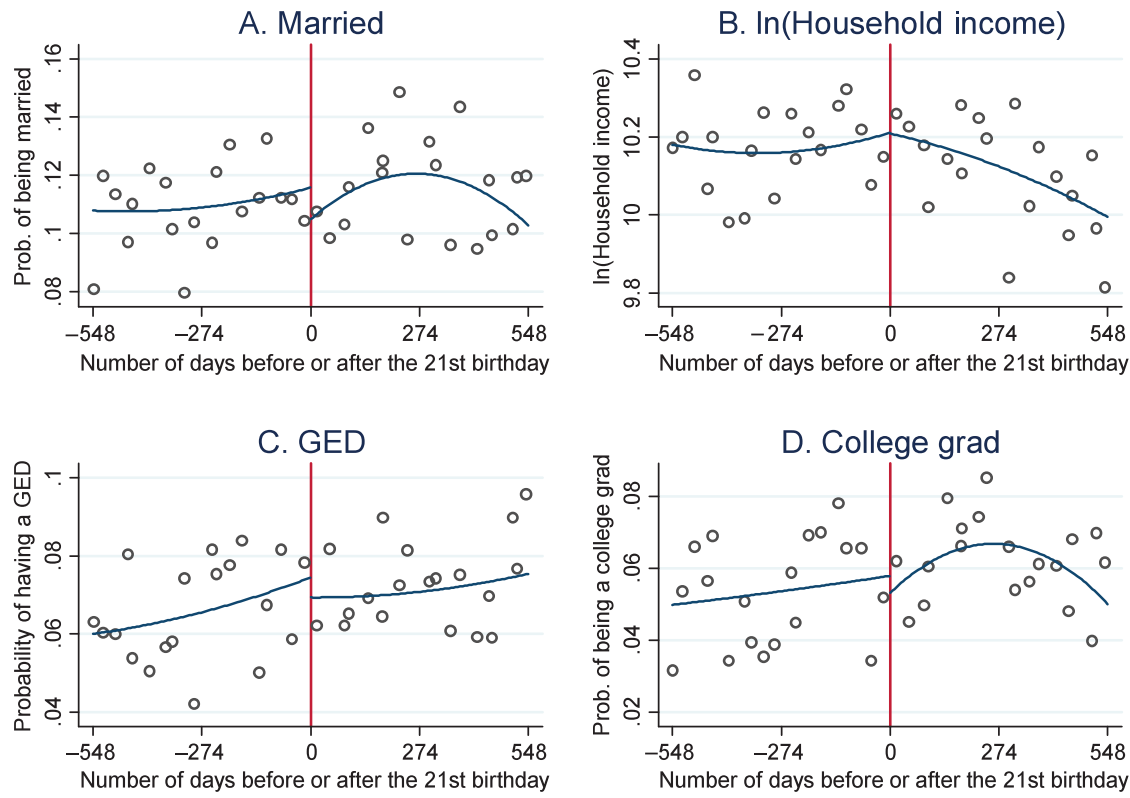

Figure 4: Trends in selected control variables before and after the 21st birthday.

Notes: Mean of the outcome variables for 30 day intervals is plotted. The solid lines are a second-order polynomial fitted on individual observations on either side of the age-21 cutoff as reported in Table 2 . 


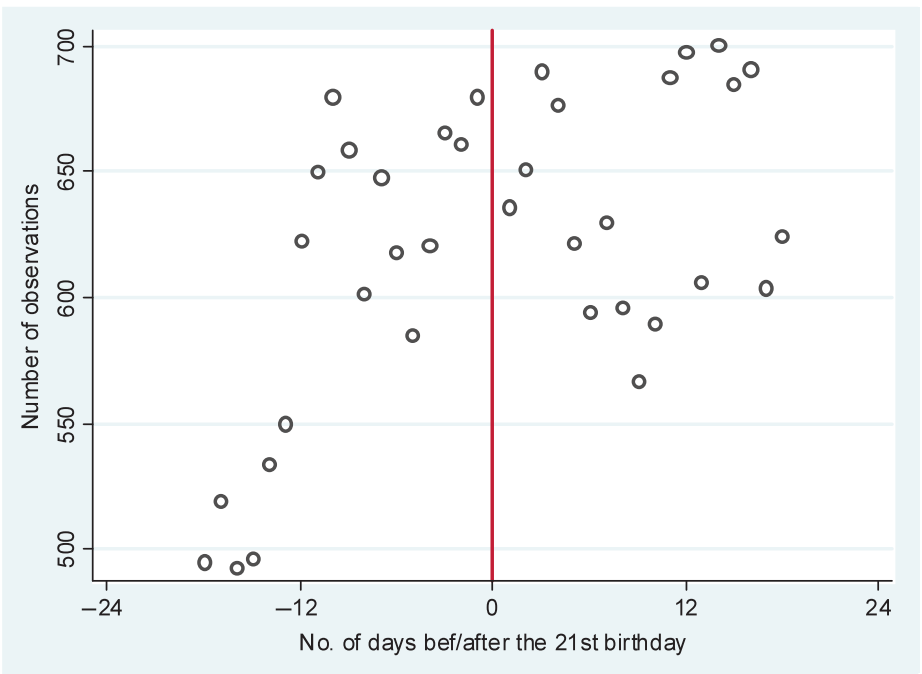

Figure 5: Distribution of the number of observations around age 21.
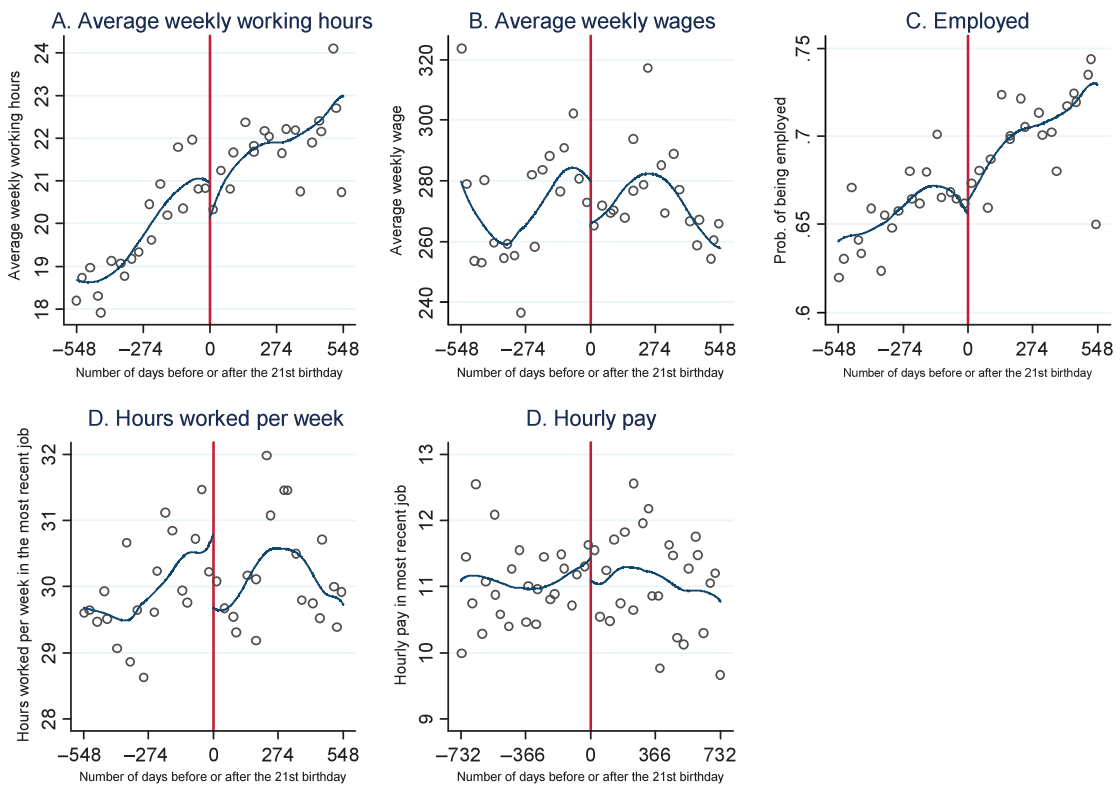

Figure 6: LOWESS estimation for selected labor market outcomes before and after the 21st birthday.

Notes: Mean of the outcome variables for 30 day intervals is plotted. The solid lines are LOWESS smoothing parameters fitted on individual observations on either side of the age-21 cutoff. 


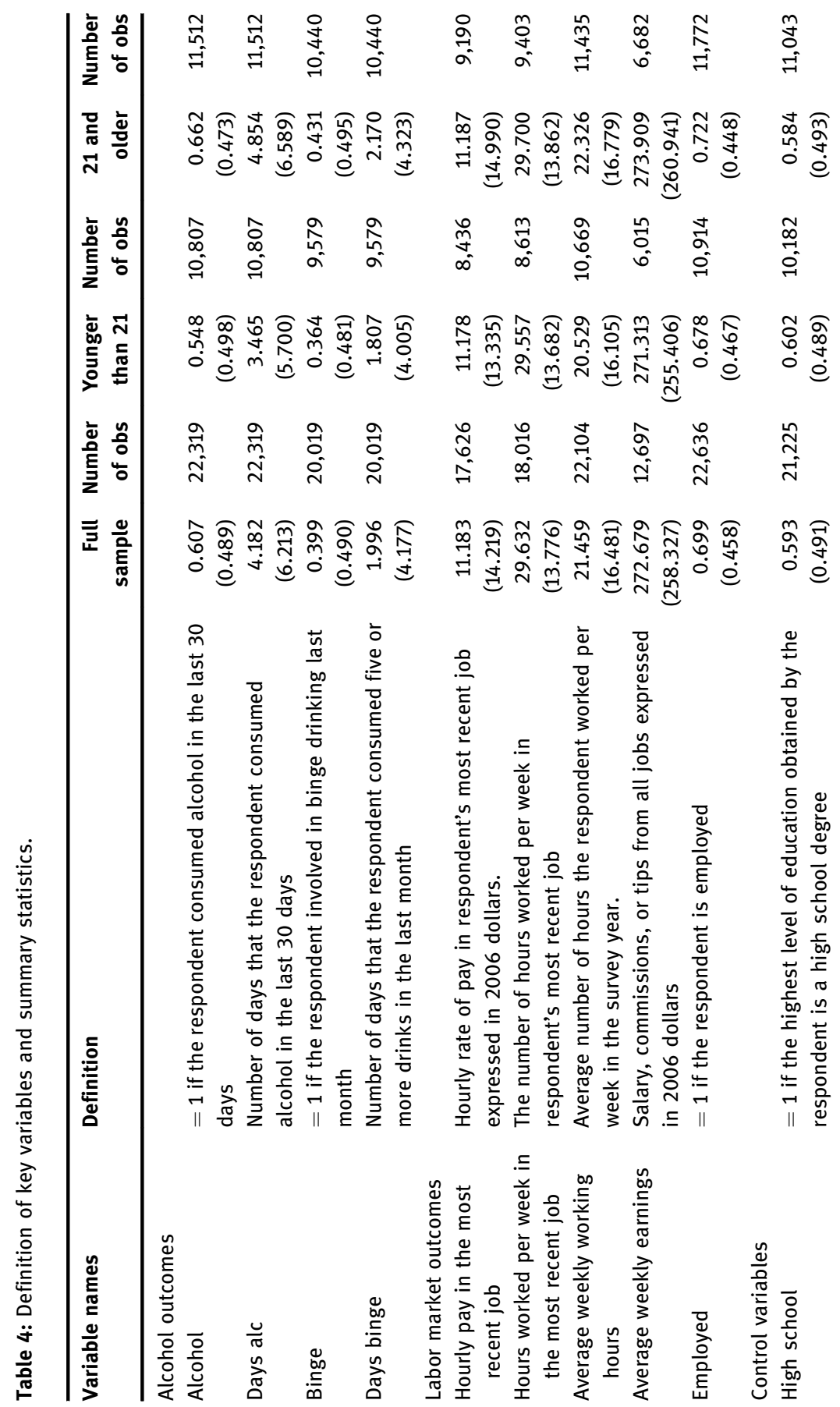




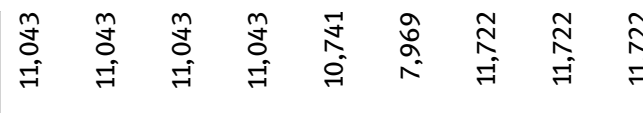

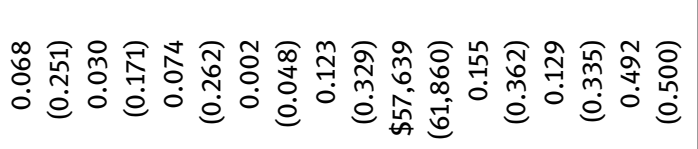

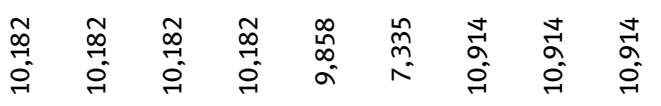

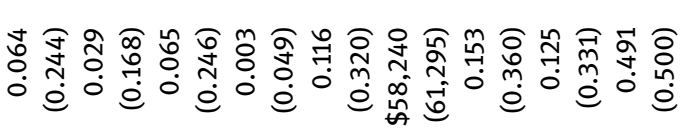

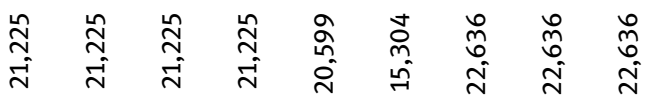

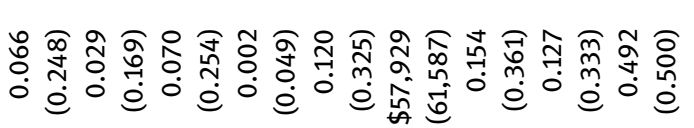

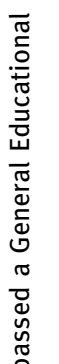

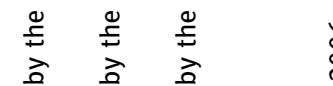

व व व

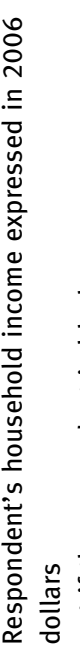

营。产。雚

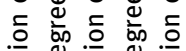

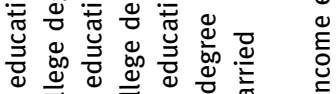

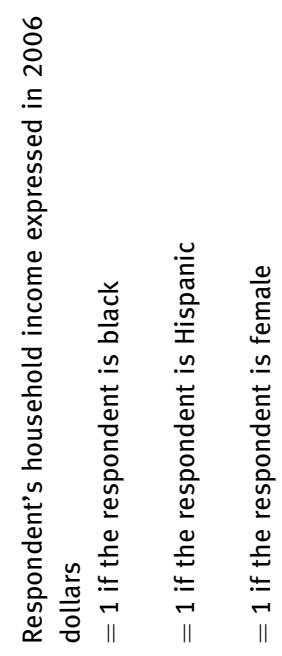

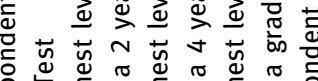

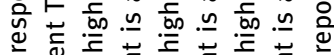

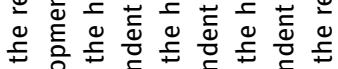

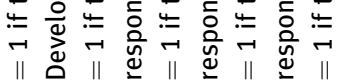

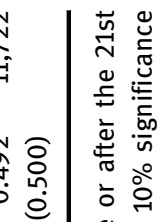

늄 $\frac{0}{\frac{0}{0}}$

空 in

중 웅

ডั

है

$\stackrel{0}{ \pm}$

뜰

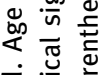

응

爱

永过

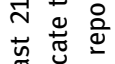

㐿

$\frac{\pi}{\pi}$.

우 *

軠

告

은 品

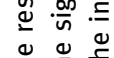

导

$\because=\dot{0}$

ธั 은

원 जั

त के

可 盯

느 . 히

들 웜

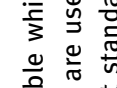

竞 壳

$\geq \sum^{2}$

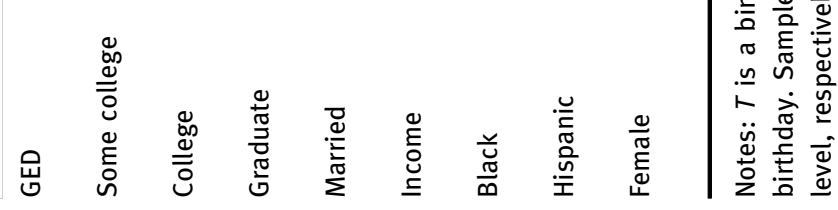




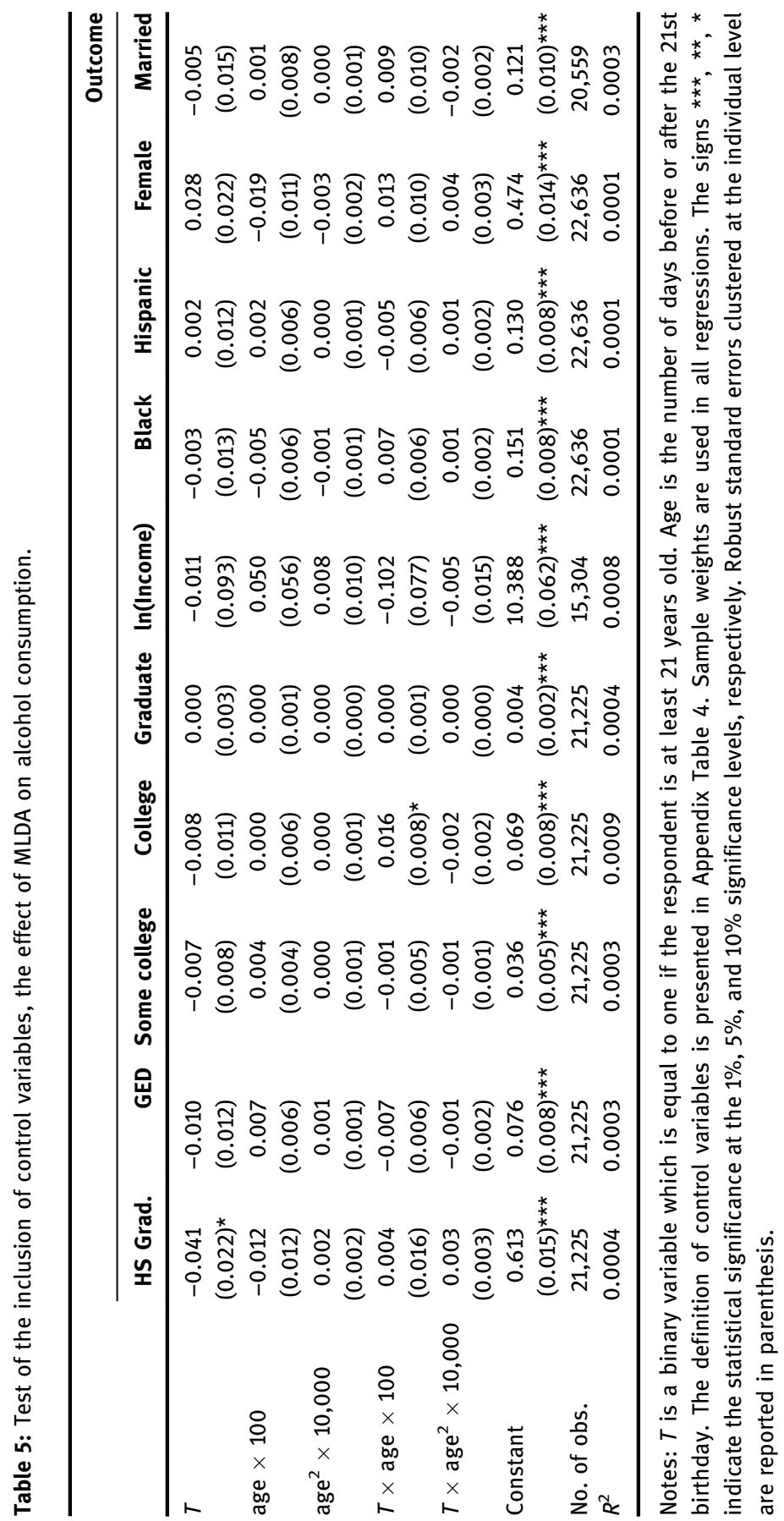




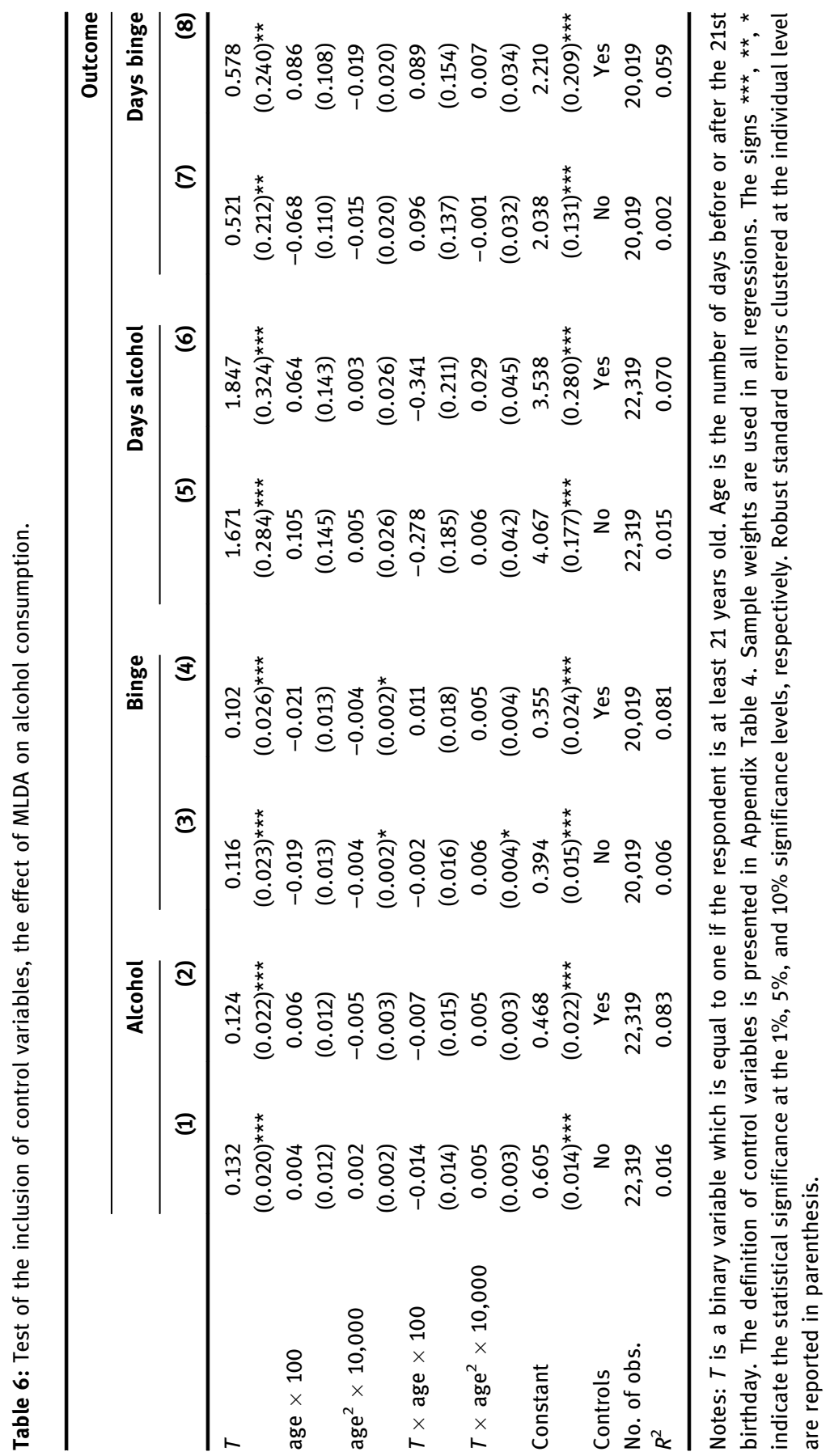




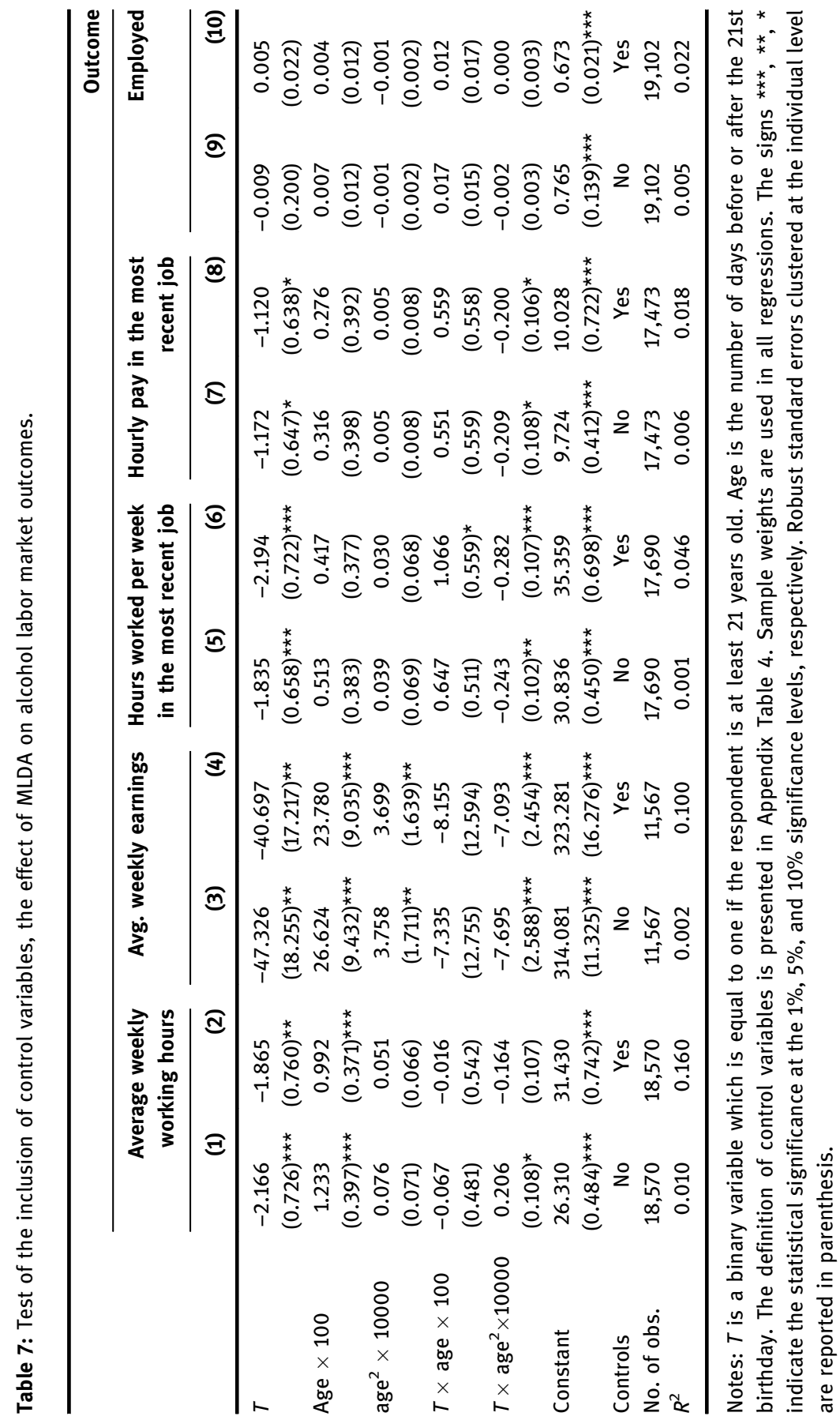




\section{References}

Bray, J. W. 2005. “Alcohol Use, Human Capital, and Wages." Journal of Labor Economics 23:279-312.

Bureau of Labor Statistics, National Longitudinal Surveys, National Longitudinal Survey of Youth. 1997. (NLSY97). http://www.bls.gov/nls/nlsy97html

Cameron, A. C., and P. K. Trivedi. 2005. Microeconomics: Methods and Applications. New York, NY: Cambridge University Press.

Carpenter, C., and C. Dobkin. 2009. "The Effect of Alcohol Consumption on Mortality: Regression Discontinuity Evidence From the Minimum Drinking Age." American Economic Journal: Applied Economics 1:164-182.

Carrell, S. E., M. Hoekstra, and J. E. West. 2011. "Does Drinking Impair College Performance? Evidence from a Regression Discontinuity Approach." Journal of Public Economics 95:54-62.

Cook, P. J., and M. Moore. 2000. "Alcohol, Handbook of Health Economics." In Handbook of Health Economics, edited byA. J. Culyer and J. P. Newhouse, Vol. 1, 1629-1673. Amsterdam, Netherlands: Elsevier. Chapter 30.

Dave, D., and R. Kaestner. 2002. "Alcohol Taxes and Labor Market Outcomes." Journal of Health Economics 21:357-371.

Fan, J., and I. Gijbels. 1996. Local Polynomial Modelling and Its Applications. London: Chapman and Hall.

French, M., and G. A. Zarkin. 1995. "Is Moderate Alcohol Use Related to Wages? Evidence from Four Worksites." Journal of Health Economics 14:319-344.

Gelman, A., and G. Imbens.2014. "Why High-Order Polynomials Should Not Be Used in Regression Discontinuity Designs.” NBER Working Paper No. 20405.

Hahn, J., P. Todd, and W. van der Klaauw. 2001. "Identification and Estimation of Treatment Effects with a Regression-Discontinuity Design." Econometrica 69:201-209.

Imbens, G., and K. Kalyanaraman. 2012. "Optimal Bandwidth Choice for the Regression Discontinuity Estimator." The Review of Economic Studies 79:933-959.

Imbens, G., and T. Lemieux. 2008. "Regression Discontinuity Designs: A Guide to Practice.” Journal of Econometrics 142:615-635.

Kenkel, D. S., and D. C. Ribar. 1994. "Alcohol Consumption and Young Adults' Socioeconomic Status." Brookings Papers on Economics Activity: Microeconomics 1994:119-175.

Lee, D. S., and T. Lemieux.2009. "Regression Discontinuity Designs in Economics.” NBER Working Paper No. 02138.

Ludwig, J., and D. Miller. 2007. "Does Head Start Improve Children's Life Chances? Evidence from a Regression Discontinuity Design.” Quarterly Journal of Economics 122:159-208.

Malamud, O., and C. Pop-Eleches. 2011. "Home Computer Use and the Development of Human Capital.” Quarterly Journal of Economics 126:987-1027.

Manning, W. G., L. Blumberg, and L. H. Moulton. 1995. "The Demand for Alcohol: The Differential Response to Price." Journal of Health Economics 14:123-148.

Manning, W. G., and J. Mullahy. 1998. "The Effect of Price on Patterns of Alcohol Consumption." Unpublished manuscript, Department of Health Studies, University of Chicago.

Markowitz, S. 2005. “Alcohol, Drugs, and Violent Crime." International Review of Law and Economics 25:20-44. 
McCrary, J. 2008. "Manipulation of the Running Variable in the Regression Discontinuity Design: A Density Test." Journal of Economic Literature 142:698-714.

Miron, J. A., and E. Tetelbaum.2007. "Does the Minimum Drinking Age Save Lives?" NBER Working Paper No. 13257.

Mullahy, J., and J. L. Sindelar. 1993. "Alcoholism, Work, and Income." Journal of Labor Economics 11:494-520.

Mullahy, J., and J. L. Sindelar. 1996. "Employment, Unemployment, and Problem Drinking.” Journal of Health Economics 15:409-434.

Renna, F. 2008. "Alcohol Abuse, Alcoholism, and Labor Market Outcomes: Looking for the Missing Link.” Industrial and Labor Relations Review 62:92-103.

Rice, D. P., S. Kelman, L. S. Miller, and S. Dunmeyer. 1990. The Economic Costs of Alcohol and Drug Abuse and Mental Illness: 1985, Institute for Health and Aging. San Diego, CA: University of California.

Yörük, B. K., and C. E. Yörük. 2011. “The Impact of Minimum Legal Drinking Age Laws on Alcohol Consumption, Smoking, and Marijuana Use: Evidence from a Regression Discontinuity Design Using Exact Date of Birth." Journal of Health Economics 30:740-752. 